\title{
Low Molecular Weight Heparin, Anti-inflammatory/Immunoregulatory and Antiviral Effects, a Short Update
}

\author{
Antonio Vitiello ${ }^{1}\left[\right.$ [ Francesco Ferrara ${ }^{2}(0)$ \\ Accepted: 25 August 2021 / Published online: 30 August 2021 \\ (c) Springer Science+Business Media, LLC, part of Springer Nature 2021
}

\begin{abstract}
Low molecular weight heparin (LMWH) is a glycosaminoglycan long known for its anticoagulant properties. In recent times, recent evidence has associated this drug with extra pleiotropic anticoagulant effects that have also proven useful in the management of the treatment of COVID-19 infection indicating that heparin may play other roles in the management of the disease in addition to the prevention of thrombosis. Clinical observations and in vitro studies support that heparin has a potential multi-target effect. To date, the molecular mechanisms of these pleiotropic effects are not fully understood. This brief review presents some of the evidence from clinical and animal studies and describes the potential molecular mechanisms by which heparin may exert its anti-inflammatory/immunoregulatory and antiviral effects.
\end{abstract}

Keywords Heparin · Cardiovascular · Extracoagulation · COVID-19 · Toxicology

\section{Introduction}

Low molecular weight heparins (LMWH) are glycosaminoglycans obtained by fractionation of heparin. They are used in the prophylaxis of venous thromboembolism in surgical patients and in the prophylaxis of venous thromboembolism in nonsurgical patients with an acute condition (such as acute heart failure, respiratory failure, severe infection, or rheumatic disease) and impaired mobility at increased risk for venous thromboembolism, in the treatment of deep vein thrombosis and pulmonary embolism, in the treatment of unstable angina and myocardial infarction without ST-segment elevation in combination with oral acetylsalicylic acid, and in the treatment of acute myocardial infarction with ST-segment elevation. [1] The pharmacological mechanisms of the anticoagulant effects of heparin are well known and described in numerous reviews of the literature. Recent evidence also associates the use of heparin with

Francesco Ferrara

ferrarafr@libero.it

Antonio Vitiello

antonio.vitiello2@uslumbria1.it

1 Pharmaceutical Department, Usl Umbria 1, XIV Settembre Street, 06132 Perugia, Italy

2 Pharmaceutical Department, Asl Napoli 3 SUD, Dell'Amicizia Street, 80035 Naples, Nola, Italy various non-anticoagulant effects. These include antiviral, anti-inflammatory/immunomodulatory properties, modulation of growth factors, and an antitumor effect. The antiinflammatory/immunomodulatory and antiviral effects [2] suggest a potential role also in the treatment of COVID-19 infection. [3-5].

\section{Antiviral}

The anticoagulant effects of heparin are well known. Recent evidence also associates the use of heparin with immunomodulatory and antiviral effects, particularly against SARS-CoV-2. In view of preclinical evidence, heparin has demonstrated at a concentration of $7.5 \mu \mathrm{g} / \mathrm{mL}$, antiviral effect on human immunodeficiency virus (HIV) infection by preventing virus cell adhesion. [6,7] Another preclinical study demonstrated that heparin has cell attachment inhibitory properties of Zika virus and dengue virus. [8] In addition, the inhibitory effect of heparin has been shown to correlate with virus infectivity in cells. The results suggest that heparin can effectively block the replication of dengue virus.[9] In addition some in vitro trials have demonstrated antiviral activity of heparin against rabies virus (RABV) by blocking viral adhesion and infection, [10] and Ebola virus in polarized Caco- 2 cells. In addition, several experimental trials have shown that heparin inhibits cellular entry 
of SARS-CoV. [11] Finally, recent evidence indicates that heparin may be a promising candidate for COVID-19 antiviral therapy. [12-15] Indeed, in addition to the preclinical evidence already described, studies suggest that heparin could inhibit cell entry of SARS-CoV and SARS-CoV-2. [16] Recent evidence indicates that heparin could be a promising candidate for antiviral therapy in COVID-19. SARSCoV-2 in addition to ACE-2 as a cell penetration receptor also uses cellular GAGs, particularly HS, as a co-receptor to affect cell surface attachment. [17] Studies have shown that heparin can inhibit cell penetration of SARS-CoV-2 by competing with HS. It has also been shown that heparanase can promote viral infection and spread. LMWH can inhibit the enzymatic activity of heparinase, inhibiting viral spread. [18].

\section{Antiflammatory}

Some recent evidence associates the use of heparin with anti-inflammatory effects. It has been shown that heparin can bind certain complement factors. Heparin interferes with both complement pathways, the classical and alternative pathways, by binding to and inhibiting the formation of several complement factors (e.g., active $\mathrm{C} 1$ complex, $\mathrm{C} 3$ convertase) as well as the membrane attachment complex, interfering with terminal cell lysis. [19] In addition, heparin can interact with pro-inflammatory cytokines and chemokines, [20] preventing these pro-inflammatory molecules from interacting with their specific receptors. Some evidence shows that heparin interferes with the adhesion of leukocytes to the endothelium. The results support the hypothesis that low molecular weight heparin inhibits neutrophil adhesion to activated endothelial cells by binding to P-selectin. [20] At the molecular level, heparin and related compounds may exert anti-inflammatory effects through the transcription factor NF- $\kappa \mathrm{B} .[21]$ Recent evidence associates the use of heparin with anti-inflammatory effects mediated by inhibition of the passage from the cytosolic compartment to the cell nucleus of the nuclear inflammatory transcription factor NF-кB.[22] Blockade of this transcription factor can potentially reduce the activation of inflammatory molecules and regulate the expression and production of pro-inflammatory cytokines, chemokines, and adhesion molecules. Heparin may inhibit neutrophil chemotaxis and leukocyte migration during inflammation. [23] In addition, heparin can bind P/L-selectin, which is involved in adhesion between leukocytes and endothelial walls. Heparin also interacts with integrin adhesion molecules, inhibiting the activation and tight adhesion of leukocytes to the endothelium [24] (Table 1).

The mechanisms by which heparin and its derivatives are able to express their anti-inflammatory properties reflect
Table 1 Antiflammatory properties of heparin, inhibition of NF- $\kappa \mathrm{B}$ transcription factor can potentially reduce the activation of inflammatory molecules and regulate the expression and production of proinflammatory cytokines, chemokines, and adhesion molecules. Heparin may inhibit neutrophil chemotaxis and leukocyte migration during inflammation

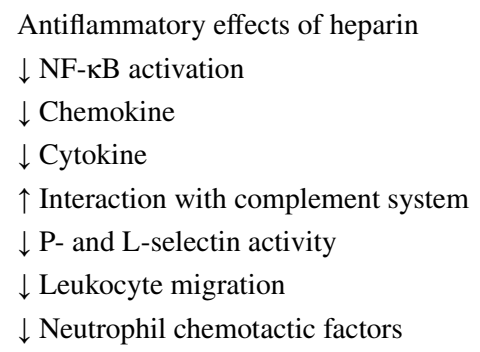

their multiple effects in biological processes. A meta-analysis demonstrates that heparin appears to be an effective anti-inflammatory agent; in reducing the level of inflammatory biomarkers and improving the condition of patients, however, data from larger and more rigorous studies are still needed to support the use of heparin as an anti-inflammatory agent in the clinical setting. [25].

\section{The Role in COVID-19}

Since the onset of the COVID-19 pandemic, several pharmacological agents have been used to avoid especially the most severe complications of infection.[26-29] Good results have been seen with some antivirals used off label, with anticoagulants, with anti-inflammatory/immunomodulatory agents. [30-33] In the most severe stages of COVID19 infection, a massive and sudden storm of cytokines is a major driver of pulmonary and extrapulmonary injury. [34, 35] Excess circulating cytokines may explain both the higher risk of thrombosis in COVID-19 patients and multi-organ failure. Clinical evidence demonstrates that IL-6 is the most frequently reported elevated cytokine and serves as a major contributor to acute inflammatory responses in COVID-19. [36] Based on this, in the most severe stages of infection, the use of pharmacologic agents that reduce the abnormal inflammatory response and risk of thrombosis, with antiviral activity, may alleviate severe symptoms and decrease COVID-19 mortality. Epidemiological data indicate among the major causes of severe COVID-19 injury is endothelial dysfunction of blood vessels. Heparinase is the endothelial glycocalyx-degrading enzyme that contributes to vascular leakage and inflammation. Low molecular weight heparins (LMWH) may inhibit heparanase. To test this hypothesis, a study of 58 individuals, 10 healthy and 48 COVID- 19 positive, showed that plasma heparanase activity was significantly elevated in COVID-19 patients, and in addition, 
heparanase activity was associated with disease severity. The use of LMWH was associated with reduced heparanase activity. [37, 38] These effects are obviously compounded by the anticoagulant efficacy of heparin. The clinical application of heparin for anticoagulant therapy in COVID-19 has shown promising results. A retrospective study including 449 patients with severe COVID-19 and inpatients [39] demonstrated that heparin therapy is associated with a better prognosis in severe COVID-19 patients.

\section{Discussions}

L'eparina è nota soprattutto per le sue proprietà anticoagulanti, in commercio è presente come l'eparina non frazionata (UFH) e l'eparina a basso peso molecolare (LMWH). L'esatto beneficio e la sicurezza dell'eparina e dei suoi derivati come agenti antinfiammatori ed antivirale in ambito clinico non sono stati ancora definitivamente dimostrati. Le prove dimostrano che sia UFH che eparina a basso peso molecolare LMWH hanno effetti pleiotropici antiffiammatori ed antivirali dimostrando di apportare benefici in patologie come asma e chirurgia della cataratta. [40] Epidemiologic data also indicate good results for use in prevention of thrombotic risk in hospitalized patients with COVID-19 for LMWH and UFH. [41] One topic being explored is the type of patients, timing, dosing, and duration of LMWH treatment in patients with COVID-19. The authors of an observational cohort in hospitalized COVID-19 patients investigated various prophylactic doses of LMWH (enoxaparin) from $40 \mathrm{mg}$ daily up to $1 \mathrm{mg} / \mathrm{kg}$ twice daily in patients admitted to intensive care units (ICUs), $0.7 \mathrm{mg} / \mathrm{kg}$ twice daily in highintensity care units, and $1 \mathrm{mg} / \mathrm{kg}$ daily in low-intensity care units. In the cohort of patients with COVID-19 treated with high dosages of enoxaparin, a $60 \%$ reduction in mortality and clinical deterioration and a $50 \%$ reduction in venous thromboembolism were observed compared with standarddose prophylaxis. However, $3 \%$ of patients on high doses of enoxaparin experienced nonfatal major bleeding. [42] Coagulopathy represents one of the most important determinants of morbidity and mortality in coronavirus-19 disease (COVID-19). Another retrospective study was conducted in a sample of 105 hospitalized patients treated with subcutaneous enoxaparin: $80 \mathrm{mg} /$ day in patients with normal weight and mild to moderate impairment or normal renal function; $40 \mathrm{mg} /$ day in severe chronic renal failure or low body weight $(<45 \mathrm{~kg}) ; 100 \mathrm{mg} / \mathrm{day}$ if body weight was greater than $100 \mathrm{~kg}$. The use of an intermediate dose of LWMH seems to be the most effective and with a higher positive benefit/ risk ratio, [43] although further studies in this direction are needed. Several protocols have been designed to evaluate the risk-benefit profile of heparin (LWMH or UFH) in COVID19 hospitalized subjects. Probably in hospitalized patients with markedly elevated D-dimers and in the absence of contraindications, prophylactic dose LMWH therapy should be considered. [44] Probably in view of the drug-drug interaction with direct oral anticoagulants and some antivirals used in COVID-19 patients, LWMH heparins should be preferred to UFH. However, the appropriate dosing regimen that can improve disease outcome in COVID-19 patients have yet to be defined in clinical trials. [45].

\section{Conclusions}

Several extra anticoagulation activities are associated with heparin use, such as anti-inflammatory and antiviral effects. In particular, these effects may potentially contribute to the management of COVID-19 disease. Numerous clinical evidences demonstrate therapeutic efficacy for heparin treatment in SARS-CoV-2 infection. Because the safety aspects of drug treatment must always be considered in addition to the clinical benefits, efforts should be focused on maximizing therapeutic effects and minimizing the adverse effects of heparin. To do this, more clinical studies are needed to provide more clinical evidence and a better understanding of the anti-inflammatory and antiviral effects of heparin.

Acknowledgements The authors have nothing to say about ethical standards, ethical approval, and funding. This manuscript is not a clinical trial and does not violate ethical rules. No funding has been received for its preparation.

Author Contribution Antonio Vitiello: conceptualization, writingoriginal draft, methodology.

Francesco Ferrara: writing-review and editing, supervision, validation.

Data Availability Data and materials are available.

Not applicable.

\section{Declarations}

Ethics Approval and Consent to Participate Not applicable.

Consent for Publication The authors certify that the manuscript is original, never submitted to other journals for publication before. They agree for publication.

Competing Interests The authors declare no competing interests.

\section{References}

1. Onishi A, St Ange K, Dordick JS, Linhardt RJ. Heparin and anticoagulation. Front Biosci (Landmark Ed). 2016;21:1372-92.

2. Cassinelli G, Naggi A. Old and new applications of non-anticoagulant heparin. Int J Cardiol. 2016;212(Suppl 1):S14-21. 
3. Vitiello A, Ferrara F. Pharmacological agents to therapeutic treatment of cardiac injury caused by Covid-19. Life Sci. 2020;262:118510.

4. Hippensteel JA, LaRiviere WB, Colbert JF, Langouët-Astrié CJ, Schmidt EP. Heparin as a therapy for COVID-19: current evidence and future possibilities. Am J Physiol Lung Cell Mol Physiol. 2020;319(2):L211-7.

5. Ferrara F, Vitiello A. Efficacy of synthetic glucocorticoids in COVID-19 endothelites. Naunyn-Schmiedeberg's Arch Pharmacol. 2021;394:1003-7.

6. Bugatti A, Paiardi G, Urbinati C, Chiodelli P, Orro A, Uggeri M, Milanesi L, Caruso A, Caccuri F, D’Ursi P, Rusnati M. Heparin and heparan sulfate proteoglycans promote HIV-1 p17 matrix protein oligomerization: computational, biochemical and biological implications. Sci Rep. 2019;9(1):15768.

7. Nassar RA, Browne EP, Chen J, Klibanov AM. Removing human immunodeficiency virus (HIV) from human blood using immobilized heparin. Biotechnol Lett. 2012;34(5):853-6.

8. Kim SY, Koetzner CA, Payne AF, Nierode GJ, Yu Y, Wang R, Barr E, Dordick JS, Kramer LD, Zhang F, Linhardt RJ. Glycosaminoglycan compositional analysis of relevant tissues in Zika virus pathogenesis and in vitro evaluation of heparin as an antiviral against Zika virus infection. Biochemistry. 2019;58(8):1155-66.

9. Lin YL, Lei HY, Lin YS, Yeh TM, Chen SH, Liu HS. Heparin inhibits dengue-2 virus infection of five human liver cell lines. Antiviral Res. 2002;56(1):93-6.

10. Sasaki M, Anindita PD, Ito N, Sugiyama M, Carr M, Fukuhara H, Ose T, Maenaka K, Takada A, Hall WW, Orba Y, Sawa $\mathrm{H}$. The role of heparan sulfate proteoglycans as an attachment factor for rabies virus entry and infection. J Infect Dis. 2018;217(11):1740-9.

11. Tamhankar M, Gerhardt DM, Bennett RS, Murphy N, Jahrling PB, Patterson JL. Heparan sulfate is an important mediator of Ebola virus infection in polarized epithelial cells. Virol J. 2018;15(1):135.

12. Hippensteel JA, LaRiviere WB, Colbert JF, Langouët-Astrié CJ, Schmidt EP. Heparin as a therapy for COVID-19: current evidence and future possibilities. Am J Physiol Lung Cell Mol Physiol. 2020;319(2):L211-7.

13. A. Vitiello, R. La Porta, V. D'Aiuto, F. Ferrara, Pharmacological approach for the reduction of inflammatory and prothrombotic hyperactive state in COVID-19 positive patients by acting on complement cascade. Human Immunology, 2021

14. Ferrara F, Vitiello A. Scientific hypothesis for treatment of COVID-19's lung lesions by adjusting ACE/ACE2 imbalance. Cardiovasc Toxicol. 2021:1-6.

15. Ayerbe L, Risco C, Ayis S. The association between treatment with heparin and survival in patients with Covid-19. J Thromb Thrombolysis. 2020;50(2):298-301.

16. Lang J, Yang N, Deng J, et al. Inhibition of SARS pseudovirus cell entry by lactoferrin binding to heparan sulfate proteoglycans. PLoS One. 2011;6(8):e23710.

17. Tandon R, Sharp JS, Zhang F, Pomin VH, Ashpole NM, Mitra D, Jin W, Liu H, Sharma P, Linhardt RJ. Effective inhibition of SARS-CoV-2 entry by heparin and enoxaparin derivatives. bioRxiv [Preprint]. 2020:2020.06.08.140236.

18. Fernández S, Moreno-Castaño AB, Palomo M, Martinez-Sanchez J, Torramadé-Moix S, Téllez A, Ventosa H, Seguí F, Escolar G, Carreras E, Nicolás JM, Richardson E, García-Bernal D, CarloStella C, Moraleda JM, Richardson PG, Díaz-Ricart M, Castro P. Distinctive biomarker features in the endotheliopathy of COVID19 and septic syndromes. Shock. 2021.

19. Hogwood J, Pitchford S, Mulloy B, Page C, Gray E. Heparin and non-anticoagulant heparin attenuate histone-induced inflammatory responses in whole blood. PLoS One. 2020;15(5):e0233644.
20. Shi C, Tingting W, Li JP, Sullivan MA, Wang C, Wang H, Deng $\mathrm{B}$, Zhang Y. Comprehensive landscape of heparin therapy for COVID-19. Carbohydr Polym. 2021;254:117232.

21. Young E. The anti-inflammatory effects of heparin and related compounds. Thromb Res. 2008;122(6):743-52.

22. Bal Dit Sollier C, Dillinger JG, Drouet L. Anticoagulant activity and pleiotropic effects of heparin. J Med Vasc. 2020;45(3):147-157.

23. Poterucha TJ, Libby P, Goldhaber SZ. More than an anticoagulant: do heparins have direct anti-inflammatory effects? Thromb Haemost. 2017;117(3):437-44.

24. Ludwig RJ. Therapeutic use of heparin beyond anticoagulation. Curr Drug Discov Technol. 2009;6(4):281-9.

25. Mousavi S, Moradi M, Khorshidahmad T, Motamedi M. Antiinflammatory effects of heparin and its derivatives: a systematic review. Adv Pharmacol Sci. 2015;2015:507151.

26. Vitiello A, Pelliccia C, Ferrara F. Drugs acting on the reninangiotensin system and SARS-CoV-2. Drug Discov Today. 2021;26(4):870-4.

27. Vitiello A, Ferrara F. Colchicine and SARS-CoV-2: management of the hyperinflammatory state. Respir Med. 2021;178:106322.

28. Vitiello A, Porta R, Pianesi L, Ferrara F. COVID-19 pandemic: vaccine and new monoclonal antibodies, point of view. Ir J Med Sci. 2021.

29. Vitiello A, Ferrara F. Pharmacological agents modifying the renin angiotensin and natriuretic peptide systems in COVID-19 patients. Wien Klin Wochenschr. 2021

30. Ferrara F, Granata G, Pelliccia C, La Porta R, Vitiello A. The added value of pirfenidone to fight inflammation and fibrotic state induced by SARS-CoV-2: anti-inflammatory and anti-fibrotic therapy could solve the lung complications of the infection? Eur J Clin Pharmacol. 2020;76(11):1615-8.

31. Ferrara F, Porta R, D'Aiuto V, Vitiello A. Remdesivir and COVID19. Ir J Med Sci. 2020;17:1-2.

32. Vitiello A, Ferrara F. Therapeutic strategies for SARS-CoV-2 acting on ACE-2. Eur J Pharm Sci. 2021;156:105579.

33. Vitiello A, Ferrara F. Remdesivir versus ritonavir/lopinavir in COVID-19 patients. Ir J Med Sci. 2020;18:1-2.

34. Vitiello A, Ferrara F. Anti-fibrotic therapy for the treatment of pulmonary sequelae in patients healed by COVID-19. Lung India. 2021;38(Supplement):S129-30.

35. Han H, Ma Q, Li C, Liu R, Zhao L, Wang W, Zhang P, Liu X, Gao G, Liu F, Jiang Y, Cheng X, Zhu C, Xia Y. Profiling serum cytokines in COVID-19 patients reveals IL-6 and IL-10 are disease severity predictors. Emerg Microbes Infect. 2020;9(1):1123-30.

36. Billett HH, Reyes-Gil M, Szymanski J, Ikemura K, Stahl LR, Lo Y, Rahman S, Gonzalez-Lugo JD, Kushnir M, Barouqa M, Golestaneh L, Bellin E. Anticoagulation in COVID-19: effect of enoxaparin, heparin, and apixaban on mortality. Thromb Haemost. 2020;120(12):1691-9.

37. Buijsers B, Yanginlar C, de Nooijer A, et al. Increased plasma heparanase activity in COVID-19 patients. Front Immunol. 2020;11:575047.

38. Clausen TM, Sandoval DR, Spliid CB, et al. SARS-CoV-2 infection depends on cellular heparan sulfate and ACE2. Cell. 2020;183(4):1043-1057.e15.

39. Tang N, Bai H, Chen X, Gong J, Li D, Sun Z. Anticoagulant treatment is associated with decreased mortality in severe coronavirus disease 2019 patients with coagulopathy. J Thromb Haemost. 2020;18(5):1094-9.

40. Mousavi S, Moradi M, Khorshidahmad T, Motamedi M. Antiinflammatory effects of heparin and its derivatives: a systematic review. Adv Pharmacol Sci. 2015;2015:507151.

41. Susen S, Tacquard CA, Godon A, Mansour A, Garrigue D, Nguyen P, Godier A, Testa S, Levy JH, Albaladejo P, Gruel Y; 
GIHP and GFHT. Prevention of thrombotic risk in hospitalized patients with COVID-19 and hemostasis monitoring. Crit Care. 2020;24(1):364.

42. Martinelli I, Ciavarella A, Abbattista M, Aliberti S, De Zan V, Folli C, Panigada M, Gori A, Artoni A, Ierardi AM, Carrafiello G, Monzani V, Grasselli G, Blasi F, Peyvandi F. Increasing dosages of low-molecular-weight heparin in hospitalized patients with Covid-19. Intern Emerg Med. 2021;16(5):1223-9.

43. Mattioli M, Benfaremo $D$, Mancini $M$, Mucci L, Mainquà $P$, Polenta A, Baldini PM, Fulgenzi F, Dennetta D, Bedetta S, Gasperoni L, Caraffa A, Frausini G. Safety of intermediate dose of low molecular weight heparin in COVID-19 patients. J Thromb Thrombolysis. 2021;51(2):286-92.

44. Paolisso P, Bergamaschi L, D’Angelo EC, Donati F, Giannella M, Tedeschi S, Pascale R, Bartoletti M, Tesini G, Biffi M, Cosmi
B, Pizzi C, Viale P, Galié N. Preliminary experience with low molecular weight heparin strategy in COVID-19 patients. Front Pharmacol. 2020;11:1124.

45. Gozzo L, Viale P, Longo L, Vitale DC, Drago F. The potential role of heparin in patients with COVID-19: beyond the anticoagulant effect. A review. Front Pharmacol. 2020;11:1307. Published 2020.

Publisher's Note Springer Nature remains neutral with regard to jurisdictional claims in published maps and institutional affiliations. 